\title{
Cannabidiol protects oligodendrocyte progenitor cells from inflammation-induced apoptosis by attenuating endoplasmic reticulum stress
}

\author{
M Mecha ${ }^{1}$, AS Torrao ${ }^{1,2}$, L Mestre ${ }^{1}$, FJ Carrillo-Salinas ${ }^{1}$, R Mechoulam $^{3}$ and C Guaza ${ }^{\star, 1}$
}

Cannabidiol (CBD) is the most abundant cannabinoid in Cannabis sativa that has no psychoactive properties. CBD has been approved to treat inflammation, pain and spasticity associated with multiple sclerosis (MS), of which demyelination and oligodendrocyte loss are hallmarks. Thus, we investigated the protective effects of CBD against the damage to oligodendrocyte progenitor cells (OPCs) mediated by the immune system. Doses of $1 \mu \mathrm{M}$ CBD protect OPCs from oxidative stress by decreasing the production of reactive oxygen species. CBD also protects OPCs from apoptosis induced by LPS/IFN $\gamma$ through the decrease of caspase 3 induction via mechanisms that do not involve CB1, CB2, TRPV1 or PPAR $\gamma$ receptors. Tunicamycin-induced OPC death was attenuated by CBD, suggesting a role of endoplasmic reticulum (ER) stress in the mode of action of CBD. This protection against ER stress-induced apoptosis was associated with reduced phosphorylation of eiF2 $\alpha$, one of the initiators of the ER stress pathway. Indeed, CBD diminished the phosphorylation of PKR and eiF2 $\alpha$ induced by LPS/IFN $\gamma$. The pro-survival effects of CBD in OPCs were accompanied by decreases in the expression of ER apoptotic effectors (CHOP, Bax and caspase 12), and increased expression of the anti-apoptotic Bcl-2. These findings suggest that attenuation of the ER stress pathway is involved in the 'oligoprotective' effects of CBD during inflammation.

Cell Death and Disease (2012) 3, e331; doi:10.1038/cddis.2012.71; published online 28 June 2012

Subject Category: Neuroscience

Cannabidiol (CBD) is the most abundant cannabinoid in Cannabis sativa that is devoid of psychoactive properties. CBD exerts anti-inflammatory, antioxidant and neuroprotective effects, ${ }^{1}$ and it has been approved for the treatment of inflammation, pain and spasticity associated with multiple sclerosis (MS). ${ }^{2}$ Studies in an animal model of EAE have shown that $\mathrm{CBD}$ ameliorates the severity of the disease by attenuating neuroinflammation and axonal damage. ${ }^{3}$ Oligodendrocyte progenitor cells (OPCs) are relatively quiescent cells derived from precursors of the perinatal CNS that make up around $5-8 \%$ of the glial cell population in the adult; in the injured CNS, they can divide and are thought to differentiate to new myelinating oligodendroytes that replace those that have been lost in demyelinating areas. ${ }^{4}$ OPCs are highly vulnerable to inflammation and oxidative stress as they have a high metabolic rate, high intracellular iron, and low concentrations of the antioxidative glutathione; they also express an arsenal of molecules rendering them susceptible to inflammatory cytokines or high calcium levels among others. ${ }^{5}$ It is known that inflammation contributes to oligodendroglial damage in demyelinating diseases such as MS. ${ }^{6}$ Synthetic cannabinoids such as WIN 55212-2 and HU211 can protect oligodendrocyte progenitors cells (OPCs) from the apoptosis induced by the withdrawal of trophic support, ${ }^{7}$ although their utility is limited due to their unwanted psychotropic effects. However, little is known about the effects of CBD on the apoptosis of OPCs induced by inflammation. Although CBD induces cytotoxicity in oligodendrocytes of the optic nerve under basal conditions by increasing intracellular calcium, ${ }^{8}$ it also prevents apoptotic signaling in neurons by reducing calcium influx. ${ }^{9}$ The pharmacological basis of the effects of CBD remains elusive, although multiple potential targets of $\mathrm{CBD}$ have been proposed in function of the stimuli and cell type involved. ${ }^{1}$

The endoplasmic reticulum (ER) stress response modulates the response of oligodendrocytes to inflammatory stimuli, ${ }^{10}$ and it involves the activation of the double-stranded RNA-activated serine/threonine kinase (PKR), which has been implicated as an important component of host responses to infection and various situations of cellular stress. ${ }^{11}$ PKR is one of the ER transmembrane protein factors that coordinates an adaptive program known as the integrated stress response by phosphorylating the translation initiation

\footnotetext{
${ }^{1}$ Department of Functional and Systems Neurobiology, Neuroimmunology Group, Cajal Institute, CSIC, Madrid, Spain; ${ }^{2}$ Department of Physiology and Biophysics, Institute of Biomedical Sciences, University of São Paulo, São Paulo, Brazil and ${ }^{3}$ Medicinal Chemistry Department, Institute of Drug Research, Hebrew University of Jerusalem, Jerusalem, Israel

${ }^{*}$ Corresponding author: C Guaza, Department of Functional and Systems Neurobiology, Neuroimmunology Group, Cajal Institute, CSIC, Avda. Dr. Arce 37, 28002 Madrid, Brazil. Tel: + 34 5854742; Fax: + 34 5854754; E-mail: cgjb@ cajal.csic.es

Keywords: cannabidiol; OPCs; inflammation; oxidative stress; ER stress; multiple sclerosis

Abbreviations: ATF-6, activation transcription factor 6; BrdU, 5-bromo-2'-deoxyuridine; CB1, cannabinoid receptor type 1; CB2, cannabinoid receptor type 2; CBD, cannabidiol; DCF-DA, 2',7'-dichlorofluorescein-diacetate; eiF2 $\alpha$, translation initiation factor $2 \alpha$; ER, endoplasmic reticulum; IFN $\gamma$, interferon-gamma; IRE1 $\alpha$, inositolrequiring enzyme $1 \alpha$; ROS, reactive oxygen species; LPS, lipopolysaccharide; MS, multiple sclerosis; NO, nitric oxide; NOS-2, nitric oxide syntase-2; OPCs, oligodendrocyte precursor cells; PKR, double-stranded RNA-activated serine/threonine kinase; PPAR $\gamma$, peroxisome proliferator-activated receptor gamma; RT-PCR, reverse transcription PCR; TRPV1, transient receptor potential cation channel subfamily V member 1; TUNEL, terminal deoxynucleotidyl transferase dUTP nick end labeling; UPR, unfolded protein response

Received 28.2.12; revised 08.5.12; accepted 11.5.12; Edited by D Bano
} 
factor $2 \alpha$ (elF $2 \alpha) .^{12}$ Oligodendrocytes produce vast amounts of myelin and they are highly sensitive to homeostatic changes in the ER. ${ }^{10}$ The most rapidly activated pathway in conditions of ER stress involves translational repression, which can be mediated by the activation of PKR among others, and results in the phosphorylation of eiF $2 \alpha .{ }^{13}$ Although this pathway appears to offer cytoprotection to a variety of cell types, ${ }^{14}$ it can also activate apoptosis in others ${ }^{15}$; particularly in oligodendrocytes the ER stress outcome may be determined by the developmental status of the cell, as in fully myelinated mature oligodendrocytes it promotes cell survival, but in actively myelinating/remyelinating oligodendrocytes leads to cell death. ${ }^{10}$ Indeed, ER stress has been linked with the apoptosis of myelinating oligodendrocytes induced by IFN $\gamma^{16}$ and during ischemia. ${ }^{17}$ Moreover, several human diseases that involve demyelination/hypomyelination appear to involve aggravated ER stress. In Charcot-Marie-Tooth disease, ${ }^{18}$ Vanishing White Matter disease, ${ }^{19,20}$ and even in immune-mediated demyelinating disorders such as $M S^{21}$ severe ER stress and activation of the unfolded protein response (UPR) are considered central to the pathogenesis of the disease.

In the present study, we provide evidence that CBD offers protection to OPCs against inflammation-induced damage, as well as protecting OPCs from oxidative stress by decreasing ROS production. Finally, we demonstrate that the protective effects of CBD against inflammatory damage and ER stress are associated with modifications in the expression of apoptotic effectors of the UPR.

\section{Results}

Dose-response studies of the effects of CBD on OPCs. As CBD has different effects on distinct cell types, we evaluated its effects on primary OPC cultures under basal conditions. In dose-response experiments $(0.1,1,2.5$ and $5 \mu \mathrm{M}) \mathrm{CBD}$ failed to induce cell death at low concentrations $(0.1$ and $1 \mu \mathrm{M}$ : Figure 1a), although some cytotoxicity was observed at higher concentrations, resulting in the death of $23.38 \pm 3.98 \%$ of cells $(P \leqslant 0.01)$ after a 24 -h exposure to $2.5 \mu \mathrm{M} \mathrm{CBD}$, and of $33.13 \pm 5.6 \%(P \leqslant 0.001)$ at $5 \mu \mathrm{M}$. Based on these findings, a dose of $1 \mu \mathrm{M}$ was selected for the subsequent experiments.

We next investigated the effect of $\operatorname{CBD}(1 \mu \mathrm{M})$ on the cell cycle by evaluating OPC proliferation. Quantification of BrdU ${ }^{+}$cells in OPC primary cultures ( $n=10000$ cells, Figure $1 \mathrm{~b})$ revealed that CBD did not increase the proliferation of OPCs in vitro $(47.65 \pm 8.61 \%)$ with respect to the controls $(48.21 \pm 10.5 \%)$. These results were confirmed by subsequently analyzing the cell cycle by flow cytometry (Figure 1c), in which no differences were observed between G0/G1, S and G2/M phases.

At doses of 0.1 and $1 \mu \mathrm{M}, \mathrm{CBD}$ has been reported to increase intracellular $\mathrm{Ca}^{2+}$ and to induce oligodendrocyte death in the optic nerve. ${ }^{8}$ Thus, we investigated whether $1 \mu \mathrm{M}$
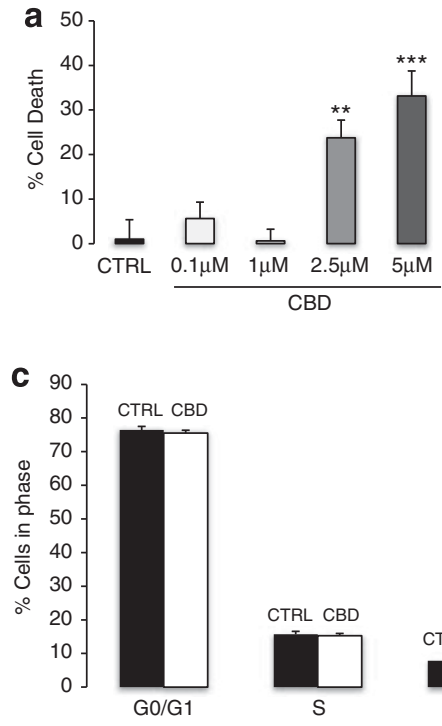
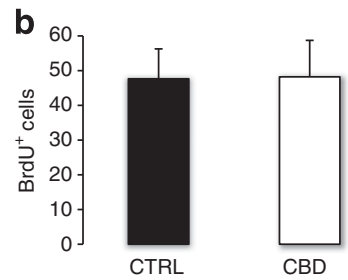

d
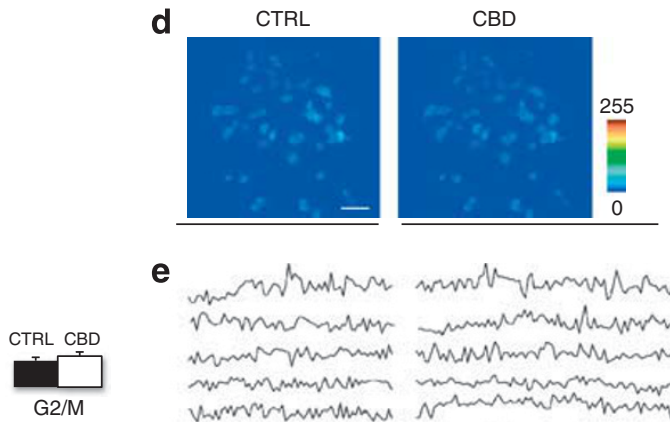

e

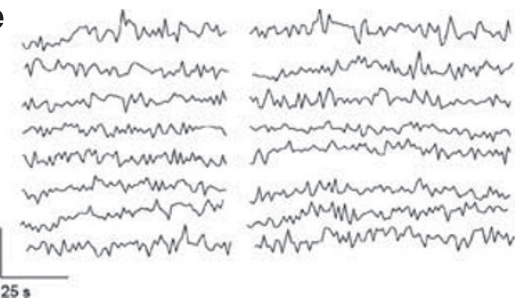

Figure 1 Effects of $\mathrm{CBD}$ on OPC cytotoxicity. (a) Although CBD did not induce cell death at low concentrations $(0.1$ and $1 \mu \mathrm{M})$, cytotoxic effects were observed at 2.5 and $5 \mu \mathrm{M}$. OPCs were exposed to CBD and cell death was quantified $48 \mathrm{~h}$ later using the LDH method. Data represent the mean \pm S.E.M. of $n=3$ cultures analyzed in triplicate. Statistical significance was determined by a one-way ANOVA: ${ }^{\star \star} P \leqslant 0.01$ and ${ }^{\star \star \star} P \leqslant 0.001$ versus untreated cells. (b) CBD did not augment OPC proliferation evident as an increase in BrdU incorporation. OPCs were incubated with BrdU $(10 \mu \mathrm{M})$ for $24 \mathrm{~h}$ and at least 10000 cells were then quantified by immunocytochemistry. (c) Flow cytometry analysis revealed the CBD does not affect the cell cycle progression of OPCs. Freshly isolated OPCs were incubated for $24 \mathrm{~h}$ in the presence or absence of CBD (1 $\mu \mathrm{M})$, and the cell cycle of a minimum of 10000 cells was analyzed on a FACSAria flow cytometer following PI staining. (d, e) CBD did not alter intracellular $\mathrm{Ca}^{2+}$ levels under basal conditions. OPCs were loaded with the $\mathrm{Ca}^{2+}$-sensitive dye Fluo-4 and the fluorescence signal was monitored on a scanning confocal microscope under basal conditions and after adding CBD ( $1 \mu \mathrm{M}: n=5$ coverslips). (d) Representative pseudocolor images showing $\mathrm{Ca}^{2+}$ levels in cultured OPCs under basal conditions and in the presence of CBD $(1 \mu \mathrm{M})$. Scale bar $=50 \mu \mathrm{m}$. (e) Fluorescence traces showing the $\mathrm{Ca}^{2+}$ time course in individual OPCs $(n=8)$ from the experiment shown in (d), both under basal conditions and in the presence of CBD. 
CBD-induced $\mathrm{Ca}^{2+}$ release from intracellular stores in cultured OPCs loaded with the $\mathrm{Ca}^{2+}$-sensitive dye, Fluo-4. There was no difference in the fluorescence signal obtained under basal conditions and in the presence of CBD ( $1 \mu \mathrm{M}$ : Figures $1 \mathrm{~d}$ and $\mathrm{e})$, indicating that intracellular $\mathrm{Ca}^{2+}$ levels were not significantly modified by CBD.

CBD protects OPCs from inflammatory stimuli and from apoptosis in a cannabinoid receptor-independent manner. As we previously reported that the LPS/IFN inflammatory stimuli induced cytotoxicity in OPCs, ${ }^{22}$ it was noteworthy that CBD $(1 \mu \mathrm{M})$ protected OPCs from the noxious effects of inflammation $(P \leqslant 0.001$, Figure $2 \mathrm{a})$, decreasing cell death from $37.84 \pm 4.95 \%$ to $10.41 \pm 4.41 \%$. Indeed, the induction of the apoptotic effector caspase 3 (Figure $2 \mathrm{~b}$ ) by LPS/IFN $\gamma$ was reversed by the treatment with CBD $(P \leqslant 0.05)$, and the number of $\mathrm{TUNEL}^{+}$cells $(24.35 \pm 1.54 \%)$ fell to control levels in the presence of CBD $(3.34 \pm 0.96 \%, P \leqslant 0.001)$ when quantified $24 \mathrm{~h}$ post treatment (Figures $2 \mathrm{c}$ and $\mathrm{d}$ ). To investigate the mechanisms underlying the oligoprotection offered by CBD, antagonists of
CB1, CB2, TRPV1 and PPAR $\gamma$ receptors were administered before the LPS/IFN $\gamma$ insult in the presence and absence of CBD. None of these antagonists reversed the protective effects of CBD observed in inflammatory conditions, suggesting that the effects of CBD are not mediated by these receptors (Figure $2 \mathrm{a}$ ).

CBD rescues OPCs from $\mathrm{H}_{2} \mathrm{O}_{2}$-induced death by decreasing ROS production. CBD is a resorcinol-based compound with direct and potent antioxidant properties; ${ }^{23}$ hence, we investigated whether CBD acts as an antioxidant in OPCs subjected to oxidative stress by evaluating its effects on the cell death and ROS production induced by hydrogen peroxide $(100 \mu \mathrm{M})$. CBD prevented the detachment and swelling of OPCs induced by direct oxidative stress (Figure $3 a$ ), and decreased cell death from $84.89 \pm 6.93 \%$ to $39.12 \pm 1.82 \%(P \leqslant 0.01$, Figure $3 b)$. Moreover, this effect was accompanied by a decrease in ROS production, as determined in DCF-DA assays $1 \mathrm{~h}$ post treatment $\mathrm{H}_{2} \mathrm{O}_{2}+$ vehicle, 216.63 $\pm 15.7 \% ; \quad \mathrm{H}_{2} \mathrm{O}_{2}+\mathrm{CBD}, \quad 151.59 \pm 5.10 \%$ : $P \leqslant 0.001$, Figure 3c). To separate the antioxidant properties a

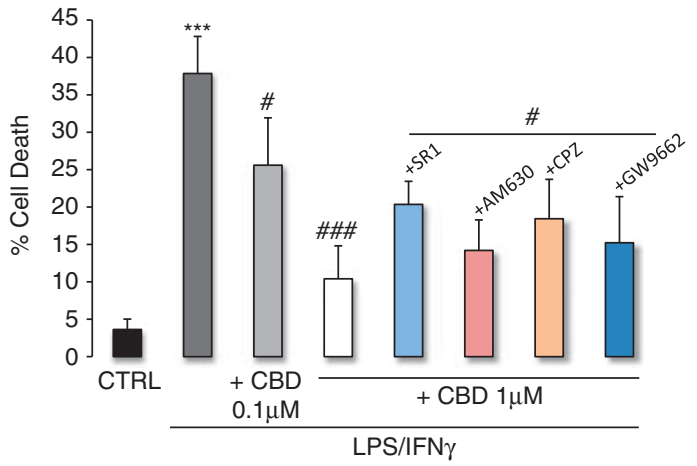

C
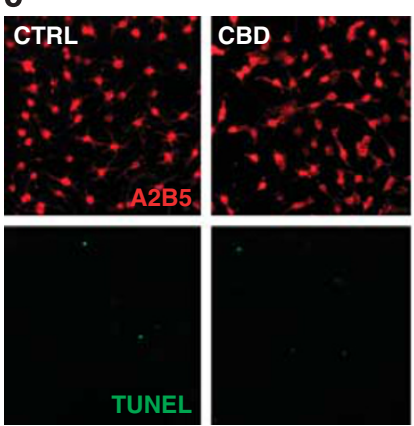
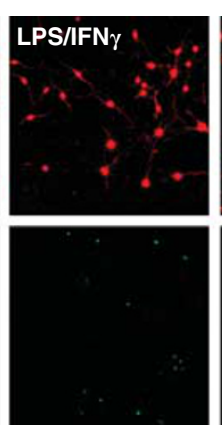

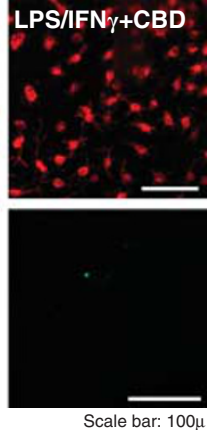

b
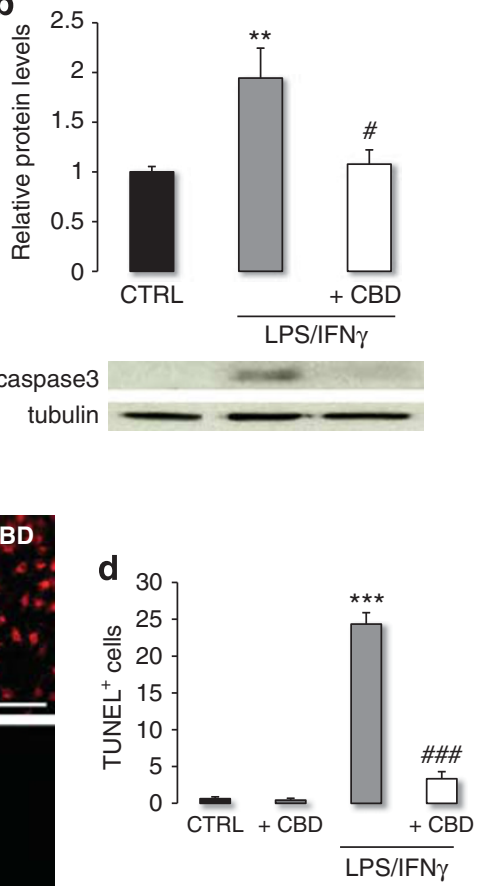

Figure 2 CBD protects against inflammatory damage by diminishing apoptosis and decreases the number of TUNEL ${ }^{+}$OPCs through a mechanism that does not involve $\mathrm{CB} 1, \mathrm{CB} 2$, TRPV1 or PPAR $\gamma$ receptors. (a) LPS/IFN $\gamma$-induced cytotoxicity in OPCs was attenuated by CBD, a dose of $1 \mu \mathrm{M}$ proving to be the most effective). Administration of CB1, CB2, TRPV1 or PPAR $\gamma$ antagonists (SR1, AM639, CPZ: $1 \mu$ M and GW9662: $50 \mathrm{nM}$ ) 30 min before the stimulus had no effect, indicating that none of these receptors are implicated in the protective effects of CBD. The data represent the mean \pm S.E.M. of $n=3$ independent cultures analyzed in triplicate, and the statistical analysis was performed using Kruskal-Wallis ANOVA followed by Mann-Whitney U test: ${ }^{* \star *} P \leqslant 0.001$ versus untreated cells, ${ }^{\#} P \leqslant 0.05$ and ${ }^{\# \# \# ~} P \leqslant 0.001$ versus cells exposed to LPS/IFN $\gamma$ alone. (b) Cleaved caspase3 western blot shows that LPS/IFN $\gamma$ treatment induces the activation of the apoptotic pathway, whereas the co-treatment with CBD reduces this induction. OPCs were incubated with LPS/IFN $\gamma$ in presence or absence of CBD $(1 \mu \mathrm{M})$. Total protein extracts were prepared $24 \mathrm{~h}$ later and cleaved caspase $3(19 \mathrm{KDa})$ was assessed in western blots probed with specific antibodies. The data represent the mean \pm S.E.M. optical density normalized to tubulin from three independent cultures analyzed in triplicate, and statistical analysis was performed using one-way ANOVA followed by the Bonferroni post-hoc test: ${ }^{* *} P \leqslant 0.01$ compared with non-treated cells, ${ }^{\#} P \leqslant 0.05$ compared with LPS/IFN $\gamma$ group. (c and d) A2B5 and TUNEL staining show that LPS/IFN $\gamma$ decreased OPC number by inducing apoptosis, an effect that was reversed by $\mathrm{CBD}$ as previously confirmed by caspase 3 measurement. OPCs were exposed for $24 \mathrm{~h}$ to the cytotoxic stimulus, in the presence or absence of CBD ( $1 \mu \mathrm{M})$, and 6000 OPCs cells were counted. Data represent the mean \pm S.E.M., and the statistical significance was determined using the Kruskal-Wallis ANOVA followed by MannWhitney $U$ test: ${ }^{* \star \star} P \leqslant 0.001$ versus untreated cells, and ${ }^{\# \# \#} P \leqslant 0.001$ versus cells exposed to LPS/IFN $\gamma$ alone 
a
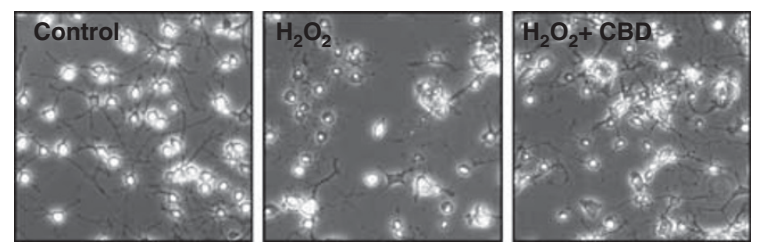

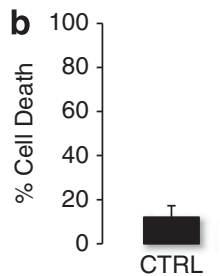

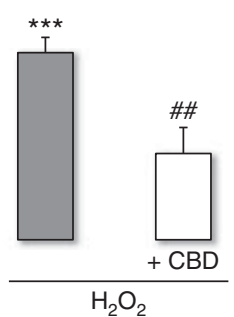
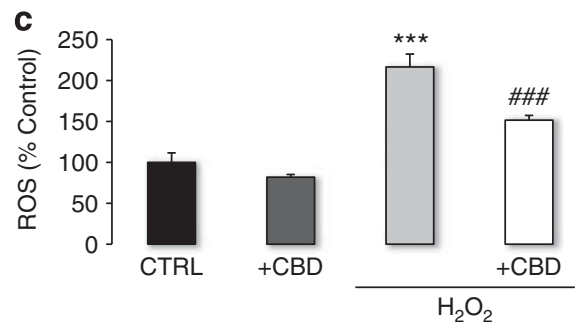

Figure 3 Oxidative stress induced by $\mathrm{H}_{2} \mathrm{O}_{2}$ induces OPC detachment and death, an effect that was attenuated by $\mathrm{CBD}$ by decreasing ROS production. (a) Phase contrast images $(\times 10)$ show that treatment with $\mathrm{H}_{2} \mathrm{O}_{2}$ induced the swelling and detachment of OPCs, an effect prevented by CBD treatment. (b) CBD protects OPCs from oxidative stress. OPCs were treated with $\mathrm{H}_{2} \mathrm{O}_{2}$ in the presence or absence of CBD $(1 \mu \mathrm{M})$ and cell death was quantified $18 \mathrm{~h}$ later using the LDH method. The data represent the mean \pm S.E.M. of four independent cultures analyzed in triplicate, and the statistical significance was determined using one-way ANOVA followed by the Bonferroni post-hoc test: ${ }^{* \star *} P \leqslant 0.001$ versus untreated cells, ${ }^{\# \#} P \leqslant 0.01$ versus cells exposed to $\mathrm{H}_{2} \mathrm{O}_{2}$ alone. (c) CBD decreased ROS production under conditions of oxidative stress. OPCs were loaded with DCF-DA for 30 min and stimulated with $\mathrm{H}_{2} \mathrm{O}_{2}$ in the presence or absence of $\mathrm{CBD}(1 \mu \mathrm{M})$. Fluorescence was measured $2 \mathrm{~h}$ later at $485 / 530 \mathrm{~nm}$ in a microplate reader and the data represent the means \pm S.E.M. of $n=3$ independent cultures analyzed in triplicate. Statistical significance was determined using Kruskal-Wallis ANOVA followed by Mann-Whitney $U$ test: ${ }^{* *} P \leqslant 0.001$ versus untreated cells, ${ }^{\# \# \#} P \leqslant 0.001$ versus cells exposed to $\mathrm{H}_{2} \mathrm{O}_{2}$ alone

of CBD of its possible cytoprotective effects on OPCs during inflammation, we also evaluated the effects of CBD on NO production in response to LPS/IFN- $\gamma$ by measuring nitrites and by western blot to assess NOS-2 expression, but CBD was not able to modify NO production (data not shown).

ER stress induces OPC death, an effect that is attenuated by CBD via decreased eiF2 $\alpha$ phosphorylation. As ER stress is implicated in several diseases with inflammatory components, such as $\mathrm{MS},{ }^{21}$ we analyzed primary OPC death in response to activation of this cellular program. Tunicamycin-induced ER stress led to OPC death $24 \mathrm{~h}$ post treatment $(45.81 \pm 4.7 \%$ : Figure $4 \mathrm{a})$, which was attenuated by treatment with CBD $(20.39 \pm 2.54 \%, P \leqslant 0.01)$. Exposure to CBD also decreased the phosphorylation of the eiF2 $\alpha$ protein $(P \leqslant 0.05)$, an initiator of the apoptotic pathway induced by ER stress (Figure 4b). Interestingly, tunicamycin-induced ER stress was not mediated by the phosphorylation of PKR, a potential activators of eiF2 $\alpha$ in the ER (data not shown).

CBD attenuates the activation of the ER apoptotic pathway in inflammatory conditions. Given the link between the mechanisms underlying inflammation and ER stress recently reported, ${ }^{24}$ we investigated the ER stress response induced by LPS/IFN $\gamma$. When we examined the effect of LPS/IFN- $\gamma$ on PKR and eiF2 $\alpha$ phosphorylation in OPCs, an increase in the phosphorylation of these proteins was evident in Western blots (Figures $4 c$ and d). Interestingly, $\mathrm{CBD}$ impaired this increase in PKR and eiF2 $\alpha$ phosphorylation, which remained at control levels $(P \leqslant 0.05)$, suggesting that one of the protective effects of CBD in OPCs involves the reduction of ER stress during neuroinflammation.

To confirm the effects of CBD in combating the ER stress associated with inflammation, we analyzed ER mediators of the apoptotic pathway. CBD significantly dampened the induction of ER pro-apoptotic molecules by LPS/IFN $\gamma$, such as the initiator CHOP, a major ER stress marker, and the effector caspase 12, as evident by real-time (RT)-PCR $(P \leqslant 0.01$ : Figure 5$)$. In addition, the balance of pro-apoptotic (Bax) and anti-apoptotic (Bcl-2) proteins, which is deregulated by LPS/IFN $\gamma$ treatment, returned to the basal state in the presence of $\mathrm{CBD}(P \leqslant 0.05)$. Furthermore, the expression of GADD34, a negative feedback protein in this pathway augmented when OPCs were treated with CBD $(P \leqslant 0.001)$, suggesting that this cannabinoid represses this apoptotic program.

\section{Discussion}

In this study, we show that the nonpsychotropic cannabinoid, $\mathrm{CBD}$, prevents OPC death induced by inflammatory, oxidative or direct ER stress. CBD does not modify the OPC cell cycle and its protective effect was unaltered by classical cannabinoid, vanilloid or PPAR $\gamma$ receptor antagonists. Moreover, the anti-apoptotic effect of CBD appears to be mediated by decreasing the expression of pro-apoptotic effectors and dampening the activity of the ER stress pathway. These findings define a novel mode of action for CBD in OPCs, supporting its therapeutic potential to protect OPCs in pathologies involving demyelination.

Neuroinflammation is one of the primary mechanisms underlying the pathogenesis of MS, and proinflammatory mediators are considered key effectors of the damage in demyelinating disorders. Indeed, previous studies have shown that inflammatory stimuli induce apoptosis in OPCs. ${ }^{6,22}$ When we initially studied the effects of CBD on primary OPC cultures, cytotoxic effects were only observed at doses $>2.5 \mu \mathrm{M}$. At doses of 0.1 and $1 \mu \mathrm{M}$, CBD was previously reported to increase intracellular calcium and 
a

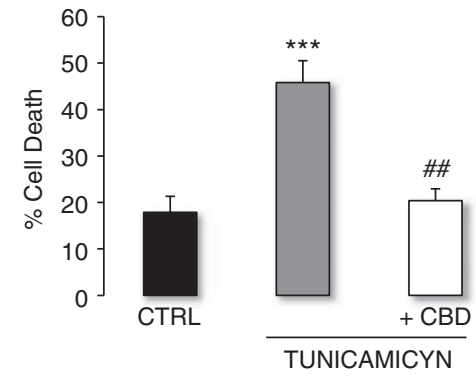

C
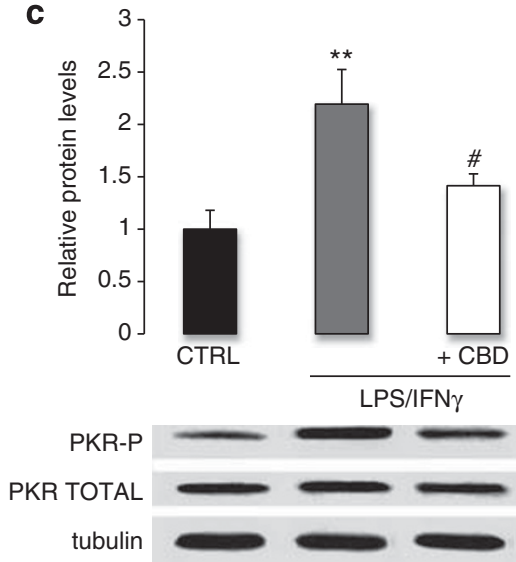

b

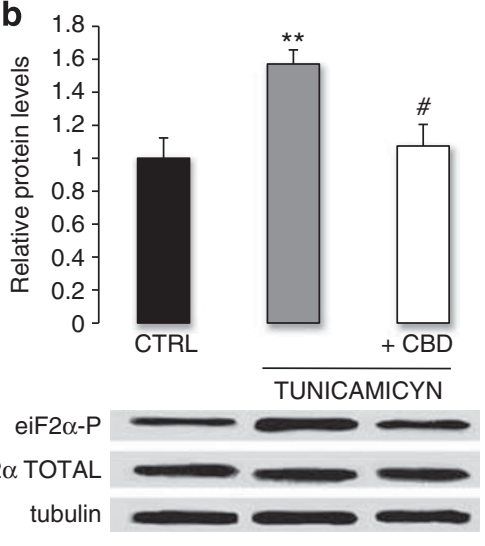

d
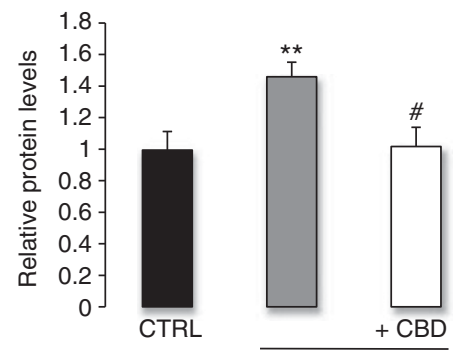

LPS/IFN $\gamma$

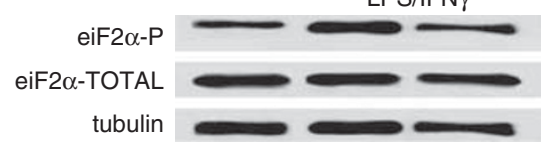

Figure 4 OPC death is mediated by ER stress, an effect that is attenuated by CBD through decreased PKR and eiF2 $\alpha$ phosphorylation in conditions of inflammation. (a) CBD attenuated tunicamycin-induced OPC death. OPCs were incubated with tunicamycin $(1 \mu \mathrm{g} / \mathrm{ml})$ in the presence or absence of CBD $(1 \mu \mathrm{M})$, and cell death was quantified $24 \mathrm{~h}$ later by the LDH method. The data represent the mean \pm S.E.M. of three independent cultures analyzed in triplicate, and the statistical significance was determined using Kruskal-Wallis ANOVA followed by Mann-Whitney $U$ test: ${ }^{* * *} P \leqslant 0.001$ versus untreated cells, ${ }^{\# \#} P \leqslant 0.01$ versus cells exposed to tunicamycin alone. (b) Tunicamycin treatment induced the eiF2 $\alpha$ phosphorylation, an effect that was attenuated by CBD. OPCs were incubated with tunicamycin ( $1 \mu \mathrm{g} / \mathrm{ml})$ in the presence or absence of $\mathrm{CBD}(1 \mu \mathrm{M})$. Total protein extracts were prepared 5 min later and the phosphorylated ( $38 \mathrm{kDa})$ and total $(38 \mathrm{kDa})$ eiF $2 \alpha$ was assessed in western blots probed with specific antibodies. The data represent the mean \pm S.E.M. optical density normalized to tubulin from four independent cultures analyzed in triplicate, and the statistical significance was determined using Kruskal-Wallis ANOVA followed by Mann-Whitney $U$ test: ${ }^{\star \star} P \leqslant 0.01$ versus untreated cells, ${ }^{\#} P \leqslant 0.05$ versus cells exposed to tunicamycin alone. (c and d) Inflammation-induced PKR and eiF2 $\alpha$ phosphorylation, an effect that was attenuated by CBD. OPCs were treated with LPS/IFN $\gamma$ in the presence or absence of CBD $(1 \mu \mathrm{M})$. Total protein extracts were prepared 5 min later and PKR (phosphorylated, $68 \mathrm{kDa}$; total, $68 \mathrm{kDa}$ ) and eiF2 $\alpha$ (phosphorylated, $38 \mathrm{kDa}$; total, $38 \mathrm{kDa}$ ) was assessed in western blots probed with specific antibodies. The data represent the mean \pm S.E.M. optical density normalized to tubulin from five cultures, and the statistical significance was determined using Kruskal-Wallis ANOVA followed by Mann-Whitney $U$ test: ${ }^{* *} P \leqslant 0.01$ versus untreated cells, ${ }^{\#} P \leqslant 0.05$ versus cells exposed to LPS/IFN $\gamma$ alone

provoke cytotoxic effects, ${ }^{8}$ although no such $\mathrm{Ca}^{2+}$ influx was observed here on exposure to $1 \mu \mathrm{M}$ CBD. These conflicting findings may reflect the different source of oligodendrocytes (optic nerve versus encephalon) and/or the state of differentiation of the cells (mature oligodendrocytes versus progenitors), pointing out to a different effect of CBD depending on the developmental state of the cell. Although $\mathrm{CBD}$ has previously been implicated in the regulation of the cell cycle, ${ }^{1}$ we ruled out this possibility by studying BrdU incorporation and cell cycle progression. Importantly, at low doses, CBD protected OPCs from LPS/IFN $\gamma$-induced cell death, evident by the reduction of caspase 3 and the number of $\mathrm{TUNEL}^{+}$cells. Although CBD protected OPCs from inflammatory damage, we did not observe alterations neither in nitrites nor NOS-2 induction by LPS/IFN- $\gamma$, indicating the lack of participation of $\mathrm{NO}$ in the protective effects of CBD. Although $\mathrm{CB} 1$ and $\mathrm{CB} 2$ receptors were expressed on OPCs, ${ }^{7}$ CBD-induced protection of OPCs was not mediated by the activation of these receptors. Blocking of vanilloid receptors or of the nuclear receptor PPAR $\gamma$ also had no effect on the capacity of CBD to protect OPCs from inflammatory damage, precluding the involvement of these receptors. These findings are consistent with reports of other effects of CBD that occur independently of classical and alternative cannabinoid receptors. $^{25}$

CBD protected OPCs from hydrogen peroxide-induced oxidative stress by diminishing ROS production, consistent with the antioxidant properties attributed to this compound in different experimental models. ${ }^{26}$ This is an important finding, as OPCs are very vulnerable to oxidative stress, ${ }^{27}$ considered to be one of the pathogenic mechanisms underlying demyelination and axonal damage in MS.

Oligodendrocytes are very sensitive to alterations in ER homeostasis. Misfolded proteins generate ER stress and contribute to cell death in pathophysiological conditions, while mutations affecting the folding of myelin constituents lead to 
a
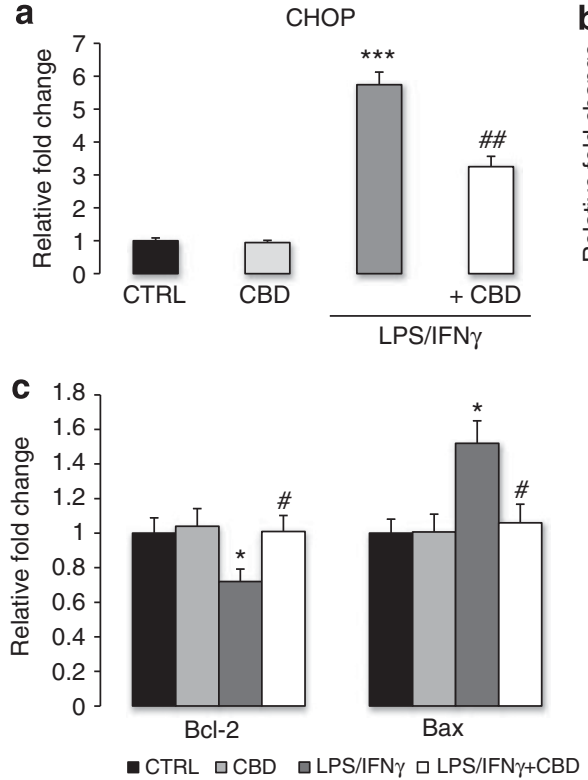

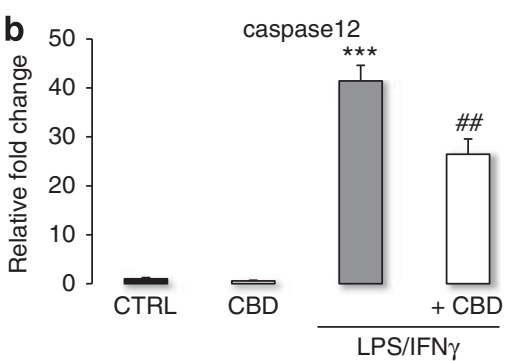

d

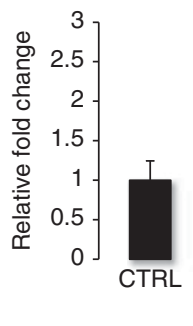

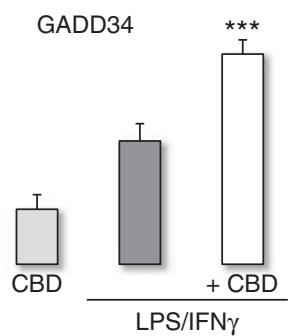

Figure 5 Inflammation activates the ER apoptotic pathway in OPCs, an effect that was attenuated by CBD. (a) CBD attenuated the inflammation-induced increase in CHOP expression. (b) The upregulation of caspase 12 expression in conditions of inflammation was attenuated by CBD. (c) CBD restores the Bcl-2/Bax balance in OPCs treated with LPS/IFN $\gamma$. (d) CBD increases the expression of the negative feedback regulator GADD34 under conditions of inflammation. In all cases, OPCs were incubated with LPS/IFN $\gamma$ in the presence or absence of CBD $(1 \mu \mathrm{M})$. The mRNA expression of each gene was measured $24 \mathrm{~h}$ later by quantitative RT-PCR and normalized to the expression of the $18 \mathrm{~S}$ gene. The data represent the mean \pm S.E.M. of three independent cultures analyzed in triplicate, and the statistical significance was determined using Kruskal-Wallis ANOVA followed by Mann-Whitney $U$ test: ${ }^{*} P<0.05,{ }^{* \star \star} P \leqslant 0.001$ versus untreated cells; and ${ }^{\#} P \leqslant 0.05,{ }^{\# \#} P \leqslant 0.01$ versus cells exposed to LPS/IFN $\gamma$ alone

oligodendrocyte death. ${ }^{28}$ We investigated the role of ER stress in OPC death in vitro. Tunicamycin, an ER stressor, induced OPC cytotoxicity through a mechanism that involved the phosphorylation of eiF2 $\alpha$, without altering PKR phosphorylation, suggesting that the induction of the UPR pathway with the tunicamycin treatment can be mediated by other ER transmembrane protein factors such as IRE1 $\alpha$ or ATF6. Activating this pathway has been linked with the developmental status of the cell ${ }^{10}$ and here we present evidence of the detrimental effects of ER stress in OPCs. The ability of CBD to protect OPCs from the damage caused by ER stress through decreasing eiF2 $\alpha$ phosphorylation highlights the potential therapeutic properties of this compound in pathological conditions in which ER homeostasis is compromised, as proposed in neurodegenerative and demyelinating diseases. ${ }^{29,30}$

There is substantial evidence linking inflammation with ER stress through several intracellular pathways. ${ }^{11,24}$ In animal models of MS, IFN $\gamma$ induces ER stress in actively myelinating oligodendrocytes, leading to apoptosis and abnormalities in neuronal myelination. ${ }^{31}$ Our results point to the crosstalk between inflammation and ER stress in OPCs, as LPS/IFN $\gamma$ induced cell death involved the phosphorylation of PKR and eiF $2 \alpha$ and hence, the apoptotic pathway activated by the UPR. This pathway has been associated with increased expression of pro-apoptotic factors, such as the $\mathrm{CHOP}$ transcription factor (C/EBP homologous protein) ${ }^{32}$ that primarily promote apoptosis by repressing $\mathrm{Bcl}-2$ expression $^{33}$ or by inducing caspase $12 .{ }^{34}$ In OPCs, we found that inflammation involved caspase 3 activation, induced the expression of $\mathrm{CHOP}$ and caspase 12, and altered the balance between Bax and $\mathrm{Bcl}-2$, implicating ER stress in cell apoptosis.
Our findings constitute the first evidence that CBD protects OPCs from inflammation-induced apoptosis by blocking ER stress. In inflammatory conditions, CBD decreased the levels of phosphorylated PKR and eiF2 $\alpha$ in OPCs. Moreover, this effect was accompanied by the restoration of CHOP, caspase 12, Bcl-2 and Bax mRNA to control levels, together with an increase in GADD34 expression, a negative feedback regulator of this pathway. ${ }^{35}$

In summary, the findings presented here indicate that low doses of CBD exert oligoprotective effects in OPCs under conditions of inflammation, oxidative and ER stress. In conditions of oxidative stress, the protective effect of CBD was mediated by a decrease in ROS production, while under neuroinflammatory conditions, CBD combated apoptosis by decreasing ER stress through the modulation of the PKR-eiF2 $\alpha$ pathway. We propose that CBD, a $C$. sativa derivative that lacks psychoactive properties, is a good candidate to protect OPCs from different cytotoxic insults, with significant therapeutic potential for the treatment of demyelinating pathologies.

\section{Material and Methods}

Animals. Animal handling and care was performed in compliance with European Union guidelines (86/609/EEC) and Spanish regulations (BOE67/8509-12; BOE1201/ 2005) regarding the use and care of laboratory animals, and all the protocols were approved by the local Animal Care and Ethics Committee of the CSIC.

Reagents. Griess reagent (sulfanilamide, $N$-(1-naphtyl)ethylenediamine), BrdU, DCFDA, hydrogen peroxide, LPS and tunicamycin were purchased from SigmaAldrich (Madrid, Spain). IFN $\gamma$ was acquired from Peprotech (London, UK), CPZ from Alexis Biochemicals (Lausen, Sweden), CBD, AM630 and GW9662 from Tocris (Bristol, UK) and SR1 was kindly provided by Sanofi-Aventis (Montpellier, France). 
Culture of oligodendrocyte progenitors. Primary cultures of OPCs derived from P0-P2 Wistar rats were prepared as described previously, ${ }^{22,36}$ with some modifications in doi:10.1038/protex.2011.218 (Open Nature exchange protocols only on line). Cells were plated on poly-o-lysine-coated plates at 50000 cells $/ \mathrm{cm}^{2}$ for western blotting or $25000 \mathrm{cells} / \mathrm{cm}^{2}$ for other assays, and they were maintained for 3 days at $37^{\circ} \mathrm{C}$ and $5 \% \mathrm{CO}_{2}$ in serum-free defined medium containing $5 \mathrm{ng} / \mathrm{ml}$ of growth factors (bFGF and PDGF-AA).

Cell toxicity. Oligodendrocyte death was quantified by measuring the release of lactate dehydrogenase (LDH) from damaged cells into the bathing medium 18, 24 and $48 \mathrm{~h}$ after exposure to hydrogen peroxide, tunicamycin and LPS/IFN $\gamma$, respectively, according to the manufacturer's instructions (cytotoxicity detection kit, Roche, Manhein, Germany). All experiments compared the cell death induced with the basal levels of cell death in the cultures.

TUNEL assay. OPCs were seeded on poly-D-lysine-coated coverslips and maintained for $24 \mathrm{~h}$ with LPS/IFN $\gamma$ and/or CBD. After they were fixed in $4 \% \mathrm{PFA}$, post-fixed in EtOH/acetic acid for $5 \mathrm{~min}$ at $-20^{\circ} \mathrm{C}$ and maintained in equilibration buffer for $1 \mathrm{~min}$, they were incubated with the TdT enzyme in a reaction buffer for $1 \mathrm{~h}$ at $37^{\circ} \mathrm{C}$ (Apoptosis detection kit, Chemicon, Millipore Ibérica, Madrid, Spain). After washing, the coverslips were incubated with the anti-DIG antibody in blocking solution and counterstained with DAPI. The data represent TUNEL ${ }^{+}$cells as a percentage of the total number of cells.

Immunocytochemistry. For BrdU analysis, OPCs were seeded on poly-Dlysine-coated coverslips and incubated with $\operatorname{BrdU}(10 \mu \mathrm{M})$ for $24 \mathrm{~h}$ in the presence or absence of CBD. Cells were then fixed in $4 \%$ PFA for 20 min, treated with $2 \mathrm{~N}$ $\mathrm{HCl}$ for $10 \mathrm{~min}$, blocked and incubated with anti-BrdU antibody (DSHB, 1:1000). After washing, the cells were incubated with an anti-mouse secondary antibody (1:1000) and counterstained with DAPI. For A2B5 staining, the cells were treated for $24 \mathrm{~h}$ with LPS/IFN $\gamma$ in the presence or absence of CBD, incubated in vivo with anti-A2B5 marker (R\&D Systems, Mineapolis, MN, USA, 1:200), fixed in 4\% PFA and incubated with the secondary antibody $(1: 1000)$.

Flow cytometry. Freshly isolated OPCs were maintained on uncoated plates for $24 \mathrm{~h}$ with vehicle or CBD. The cells were then collected, fixed in cold $70 \%$ ethanol for $30 \mathrm{~min}$, resuspended in phosphate buffer saline (PBS) and incubated with $100 \mu \mathrm{g} / \mathrm{ml}$ Ribonuclease A (Sigma-Aldrich) and $50 \mu \mathrm{g} / \mathrm{ml}$ propidium iodide (PI; Sigma-Aldrich) for $30 \mathrm{~min}$. Argon laser excitation at $488 \mathrm{~nm}$ was used to measure PI fluorescence through a band-pass $616 / 23 \mathrm{~nm}$ filter using a FACSAria flow cytometer (BD Biosciences, San Diego, CA, USA). Debris and duplets were excluded from the analysis and a minimum of 10000 cells were acquired in each experiment. FACSDiva analysis software (BD Biosciences) was used to define the cell cycle stages.

Measurement of intracellular $\mathbf{C a}^{2+}$. Cells were seeded on coverslips and incubated for $20-30 \mathrm{~min}$ at $37^{\circ} \mathrm{C}$ in PBS containing Fluo4-AM $(0.3 \mu \mathrm{M}$ Invitrogen, Barcelona, Spain) and pluronic F-127 (0.04\%, Sigma-Aldrich). The coverslips were then transferred to the microscope chamber and bathed in an extracellular medium containing (in $\mathrm{mM}$ ): $\mathrm{NaCl} 140, \mathrm{KCl} 5, \mathrm{MgCl}_{2} 4$, HEPES 10, glucose 10 and sucrose $6(\mathrm{pH} 7.35)$. All experiments were performed at room temperature. Cells were imaged with an Olympus (Barcelona, Spain) FV3 scanning confocal microscope equipped with a $\times 40$ objective (NA, 0.8 ) and laser emission at $488 \mathrm{~nm}$ was used to excite Fluo-4. The fluorescent signal recorded is displayed as a pseudocolor image and the look-up-table used is indicated in each figure. The time frame acquisition was $1.12 \mathrm{~s}$

ROS determination. OPCs were loaded with dichlorodihydrofluorescein diacetate acetyl ester (DCFDA, $2 \mu \mathrm{M}$ ) for $30 \mathrm{~min}$, washed and stimulated with hydrogen peroxide for $2 \mathrm{~h}$ or with LPS/IFN $\gamma$ for $24 \mathrm{~h}$ in the presence or absence of CBD. Fluorescence was measured at $485 / 530 \mathrm{~nm}$ in a microplate reader and normalized to the negative control.

Western blot analysis. Western blot analysis was performed as previously described ${ }^{7}$ using $30-40 \mu \mathrm{g}$ of OPC protein extract and an anti-cleaved caspase 3 $\left(\right.$ Asp $^{175} ; 1: 1000$, Cell Signaling Technology, Denvers, MA, USA), anti-phospho $\left(S^{51}{ }^{11}\right)$ elF2 $\alpha$ (1:1000; Cell Signaling Technology), anti-total elF2 $\alpha$ (1:1000; Cell Signaling Technology), anti-phospho (Thr $\left.{ }^{46}\right)$ PKR (1:1000, Upstate, Millipore Ibérica, Madrid, Spain) and anti-total PKR (1:1000, Millipore, Madrid, Spain). Anti$\alpha$-tubulin (1:40 000; Sigma-Aldrich) was used as a loading control.
RNA extraction, reverse transcription and RT-PCR. Total OPC RNA was extracted using the RNeasy mini columns kit (Qiagen, Crawley, UK) and treated with DNasel (Qiagen), and the RNA concentration and purity were determined in a Nanodrop spectrophotometer (Nanodrop Technologies, Wilmington, DE, USA). Total RNA $(1 \mu \mathrm{g})$ was reverse transcribed using the Promega reverse transcription kit (Promega, Madrid, Spain) and RT-PCR was performed on $1 \mu \mathrm{l}$ of CDNA (corresponding to $50 \mathrm{ng}$ RNA input) with $200 \mathrm{nM}$ of the primers listed below (Applied Biosystems, Warrington, UK), quantifying expression using SYBR Green (Applied Biosystems). The amplification cycles involved an initial activation step at $50^{\circ} \mathrm{C}$ for $2 \mathrm{~min}$ and a denaturation step at $95^{\circ} \mathrm{C}$ for $10 \mathrm{~min}$, followed by 40 cycles of denaturation at $95^{\circ} \mathrm{C}$ for $15 \mathrm{~s}$ and annealing/extension at $60^{\circ} \mathrm{C}$ for $1 \mathrm{~min}$. PCR assays were carried out in 96-well plates using a 7500 RealTime PCR system (Applied Biosystems). Each sample was assayed in duplicate and a 6-point standard curve was run in parallel. The ratio between the values obtained for each gene and the $18 \mathrm{~S}$ house-keeping gene provided a relative quantification of expression. The $5^{\prime}-3^{\prime}$ primer secuences used were the following: CHOP (forward 5'-CCAAAATAACAGCCGGAACCT-3'; reverse 5'-CAAAGGCG AAAGGCAGAGACT-3'), GADD34 (forward 5'-AGCATGGACACGCCTTAGA AA-3'; reverse $5^{\prime}$-AGGCTGGGAGGAGGGATTT-3'), Bax (forward $5^{\prime}$-GGGT GGCAGCTGACATGTTT-3'; reverse 5'-TGATCAGCTCGGGCACTTTA-3'), Bcl-2 (forward 5'-TGAGAGCAACCGAACGCCCG-3'; reverse 5'-CCGTGGCAAAG CGTCCCCTC-3'), caspase 12 (forward 5'-GAAGGAAGGCCGAACCCGCC-3'; reverse $5^{\prime}$-TGCTCTGGACGGCCAGCAAAC- $3^{\prime}$ ) and $18 \mathrm{~S}$ (forward $5^{\prime}$-ATGCTCTT AGCTGAGTGTCCCG-3'; reverse 5'-ATTCCTAGCTGCGGTATCCAGG-3')

Data analysis. All data are expressed as the mean \pm S.E.M. $(n)$, where $n$ refers to the number of cultures assayed, each obtained from a different group of animals and evaluated in triplicate. One-way ANOVA followed by the Bonferroni post-hoc test, or Kruskal-Wallis ANOVA followed by Mann-Whitney $U$ test was used to determine the statistical significance in all cases. The level of significance was set at $P<0.05$.

\section{Conflict of Interest}

The authors declare no conflict of interest.

Acknowledgements. We acknowledge the financial support of the Ministry of Science and Innovation (MICINN, project SAF-2010/17501), Instituto de Salud Carlos III (project RD07/0060/0010 RETICS program, Red Española de Esclerosis Múltiple, REEM). Mecha $M$ is supported by REEM. We thank to Alfonso Araque and Eduardo D Martín for their help with electrophysiological studies. We are also grateful to Joaquín Sancho and Elisa Baides Rosell for their excelent technical assistance.

1. Izzo AA, Borrelli F, Capasso R, Di Marzo V, Mechoulam R. Non-psychotropic plant cannabinoids: new therapeutic opportunities from an ancient herb. Trends Pharmacol Sci 2009; 30: 515-527.

2. Sastre-Garriga J, Vila C, Clissold S, Montalban X. THC and CBD oromucosal spray (Sativex $(\mathrm{R}))$ in the management of spasticity associated with multiple sclerosis. Expert Rev Neurother 11: 627-637.

3. Kozela E, Lev N, Kaushansky N, Eilam R, Rimmerman N, Levy R et al. Cannabidiol inhibits pathogenic $T$ cells, decreases spinal microglial activation and ameliorates multiple sclerosis-like disease in C57BL/6 mice. Br J Pharmacol 163: 1507-1519.

4. Levine JM, Reynolds R, Fawcett JW. The oligodendrocyte precursor cell in health and disease. Trends Neurosci 2001; 24: 39-47.

5. Bradl M, Lassmann H. Oligodendrocytes: biology and pathology. Acta Neuropathol 2010; 119: 37-53.

6. Lehnardt S, Lachance C, Patrizi S, Lefebvre S, Follett PL, Jensen FE et al. The toll-like receptor TLR4 is necessary for lipopolysaccharide-induced oligodendrocyte injury in the CNS. J Neurosci 2002; 22: 2478-2486.

7. Molina-Holgado E, Vela JM, Arévalo-Martín A, Almazán G, Molina-Holgado F, Borrel J, Guaza C. Cannabinoids promote oligodendrocyte progenitor survival: involvement of cannabinoid receptors and phosphatidylinositol-3 kinase/Akt signaling. J Neurosci 2002; 22: $9742-9753$.

8. Mato S, Victoria Sanchez-Gomez M, Matute C. Cannabidiol induces intracellular calcium elevation and cytotoxicity in oligodendrocytes. Glia 58 1739-47.

9. Alvarez FJ, Lafuente H, Rey-Santano MC, Mielgo VE, Gastiasoro E, Rueda M et al. Neuroprotective effects of the nonpsychoactive cannabinoid cannabidiol in hypoxicischemic newborn piglets. Pediatr Res 2008; 64: 653-658. 
10. Lin W, Popko B. Endoplasmic reticulum stress in disorders of myelinating cells. Nat Neurosci 2009; 12: 379-385.

11. Lee JH, Park EJ, Kim OS, Kim HY, Joe EH, Jou I et al. Double-stranded RNA-activated protein kinase is required for the LPS-induced activation of STAT1 inflammatory signaling in rat brain glial cells. Glia 2005; 50: 66-79.

12. Proud CG. elF2 and the control of cell physiology. Semin Cell Dev Biol 2005; 16 : $3-12$.

13. Harding HP, Novoa I, Zhang Y, Zeng H, Wek R, Schapira M et al. Regulated translation initiation controls stress-induced gene expression in mammalian cells. Mol Cell 2000; 6 : 1099-1108.

14. Lu PD, Jousse C, Marciniak SJ, Zhang Y, Novoa I, Scheuner D et al. Cytoprotection by preemptive conditional phosphorylation of translation initiation factor 2. EMBO J 2004; 23: 169-179.

15. Southwood CM, Garbern J, Jiang W, Gow A. The unfolded protein response modulates disease severity in Pelizaeus-Merzbacher disease. Neuron 2002; 36: 585-596.

16. Lin W, Harding HP, Ron D, Popko B. Endoplasmic reticulum stress modulates the response of myelinating oligodendrocytes to the immune cytokine interferon-gamma. J Cell Biol 2005; 169: 603-612.

17. Kraskiewicz H, FitzGerald U. Partial XBP1 knockdown does not affect viability of oligodendrocyte precursor cells exposed to new models of hypoxia and ischemia in vitro. J Neurosci Res 89: 661-673.

18. Pennuto M, Tinelli E, Malaguti M, Del Carro U, D'Antonio M, Ron D et al. Ablation of the UPR-mediator $\mathrm{CHOP}$ restores motor function and reduces demyelination in CharcotMarie-Tooth 1B mice. Neuron 2008; 57: 393-405.

19. van der Voorn JP, van Dijk J, Garbern J, Thomas AA, Scheper GC, Powers JM et al. The unfolded protein response in vanishing white matter disease. J Neuropathol Exp Neurol 2005; 64: 770-775.

20. van Kollenburg B, van Dijk J, Garbern J, Thomas AA, Scheper GC, Powers JM et al. Gliaspecific activation of all pathways of the unfolded protein response in vanishing white matter disease. J Neuropathol Exp Neurol 2006; 65: 707-715.

21. Mhaille AN, McQuaid S, Windebank A, Cunnea P, McMahon J, Samali A et al. Increased expression of endoplasmic reticulum stress-related signaling pathway molecules in multiple sclerosis lesions. J Neuropathol Exp Neurol 2008; 67: 200-211.

22. Molina-Holgado E, Vela JM, Arévalo-Martín A, Guaza C. LPS/IFN-gamma cytotoxicity in oligodendroglial cells: role of nitric oxide and protection by the anti-inflammatory cytokine IL-10. Eur J Neurosci 2001; 13: 493-502.

23. Hampson AJ, Grimaldi M, Axelrod J, Wink D et al. Cannabidiol and (-)Delta9tetrahydrocannabinol are neuroprotective antioxidants. Proc Natl Acad Sci USA 1998; 95: 8268-8273.

24. Zhang K, Kaufman RJ. From endoplasmic-reticulum stress to the inflammatory response. Nature 2008; 454: 455-462.
25. Lim MP, Devi LA, Rozenfeld R. Cannabidiol causes activated hepatic stellate cell death through a mechanism of endoplasmic reticulum stress-induced apoptosis. Cell Death Dis 2012; 10: 212-215.

26. El-Remessy AB, Tang Y, Zhu G, Matragoon S, Khalifa Y, Liu EK et al. Neuroprotective effects of cannabidiol in endotoxin-induced uveitis: critical role of p38 MAPK activation. Mol Vis 2008; 14: 2190-2203.

27. Back SA, Gan X, Li Y, Rosenberg PA, Volpe JJ. Maturation-dependent vulnerability of oligodendrocytes to oxidative stress-induced death caused by glutathione depletion. J Neurosci 1998; 18: 6241-6253.

28. Gow A, Southwood CM, Lazzarini RA. Disrupted proteolipid protein trafficking results in oligodendrocyte apoptosis in an animal model of Pelizaeus-Merzbacher disease. J Cell Biol 1998; 140: 925-934.

29. Stefani IC, Wright D, Polizzi KM, Kontoravdi C. The role of ER stress-induced apoptosis in neurodegeneration. Curr Alzheimer Res 2012; 9: 373-387.

30. Hoozemans JJ, van Haastert ES, Nijholt DA, Rozemuller AJ, Scheper W. Activation of the unfolded protein response is an early event in Alzheimer's and Parkinson's disease. Neurodegener Dis (in press).

31. Lin W, Kemper A, Dupree JL, Harding HP, Ron D, Popko B. Interferon-gamma inhibits central nervous system remyelination through a process modulated by endoplasmic reticulum stress. Brain 2006; 129(Pt 5): 1306-1318.

32. Ron D, Habener JF. CHOP, a novel developmentally regulated nuclear protein that dimerizes with transcription factors C/EBP and LAP and functions as a dominant-negative inhibitor of gene transcription. Genes Dev 1992; 6: 439-453.

33. Gotoh T, Terada K, Mori M. hsp70-DnaJ chaperone pairs prevent nitric oxide-mediated apoptosis in RAW 264.7 macrophages. Cell Death Differ 2001; 8: 357-366.

34. Nakagawa T, Zhu H, Morishima N, Li E, Xu J, Yankner BA, Yuan J. Caspase-12 mediates endoplasmic-reticulum-specific apoptosis and cytotoxicity by amyloid-beta. Nature 2000; 403: 98-103.

35. Novoa I, Zeng H, Harding HP, Ron D. Feedback inhibition of the unfolded protein response by GADD34-mediated dephosphorylation of elF2alpha. J Cell Biol 2001; 153: 1011-1022.

36. Almazan G, Afar DE, Bell JC. Phosphorylation and disruption of intermediate filament proteins in oligodendrocyte precursor cultures treated with calyculin. J Neurosci Res 1993; 36: $163-172$

Cell Death and Disease is an open-access journal published by Nature Publishing Group. This work is licensed under the Creative Commons Attribution-NonCommercial-No Derivative Works 3.0 Unported License. To view a copy of this license, visit http://creativecommons.org/licenses/by-nc-nd/3.0/ 